\title{
A Framework for Collaborative Networked Learning in Higher Education: Design \& Analysis
}

\author{
http://dx.doi.org/10.3991/ijet.v9i8.3903 \\ Ghassan F. Issa, Haya A. El-Ghalayini, Ahmad F. Shubita, Mohammed H. Abu-Arqoub \\ University of Petra, Amman, Jordan
}

\begin{abstract}
This paper presents a comprehensive framework for building collaborative learning networks within higher educational institutions. This framework focuses on systems design and implementation issues in addition to a complete set of evaluation, and analysis tools. The objective of this project is to improve the standards of higher education in Jordan through the implementation of transparent, collaborative, innovative, and modern quality educational programs. The framework highlights the major steps required to plan, design, and implement collaborative learning systems. Several issues are discussed such as unification of courses and program of studies, using appropriate learning management system, software design development using Agile methodology, infrastructure design, access issues, proprietary data storage, and social network analysis (SNA) techniques.
\end{abstract}

Index Terms - collaborative learning; networked learning; social network analysis; network design; learning community.

\section{INTRODUCTION}

This paper is based on a proposal for the implementation of a major project that connects several higher educational institutions in Jordan in a collaborative networked environment. The paper will formulate the implementation steps into a general framework that can be easily adopted by similar projects.

Jordan is considered one of the leading countries in the Middle East in higher education, and the first in the area to implement privatization of quality higher education. However, in the past few years, several factors have been negatively affecting higher education in Jordan including the incompatibility of learned skills and those required by employers, outdated teaching and learning methods, and the inefficient use of technology in education [1].

Development of Jordan society in recent years is going through major transformations in terms of socio-economic and political issues, change of priorities in life, moral concepts, and moral norms. Social changes posed new challenges for higher education requiring a revision of traditional teaching methods, technologies, and services. The ongoing reform of the educational system in Jordan aims at creating the necessary conditions for achieving high quality learners, who will successfully interact in a national and international cooperative environment. However, we believe that reform efforts must take into account some serious challenges related to learning, research, community service, and innovation. Currently, higher educational institutions in Jordan suffer from the lack of collaboration or linkage with secondary educational system, industry, research groups and research centers, and innovations. There are hardly any existing learning community spaces that engage policy makers, educators, civil societies, or the new generation of millennium students. Needless to say, there are virtually no existing learning communities, nor a reasonable technological infrastructure that facilitate proper collaboration between existing higher educational institutions.

To overcome the above mentioned shortcomings, this paper presents a framework that takes advantage of the latest development of Information and communication technologies (ICT), and social networking to connect several higher educational institutions in Jordan in a collaborative networked environment. The implementation of the proposed framework aims at enhancing higher education from different perspectives including policy makers, administrators, teachers, researchers, and students.

The proposed framework employs ICT to enable educators to adopt new learning methods for the realization of modern concepts in education based on learner-centered approaches utilizing social constructivism learning theory such as: network-based learning, problem-based learning, collaborative learning, and competition-based learning [2], that reflect the basic ideas and principles of humanistic pedagogy.

The work introduced in this paper is based on Vygotsky's theory [3] which states that collaborative learning is a cognitive development that depends on full social interaction which leads onto online learning communities that include interactivity, social context, and technologies. Additionally, this research relies on the community of inquiry framework $[4,5]$ for defining blended learning. In the next section we will shed some light on some of the major issues that relate directly to our proposed project including blended learning, collaborative learning, and networked learning.

\section{BACKGROUND}

\section{A. Blended Learning}

Blended learning or as sometimes referred to as "hybrid", "technology-mediated instruction", "webenhanced instruction", or "mixed-mode instruction", is a student centered (constructivist) approach based on faceto-face and computer mediated learning which blends collaborative and self-reflective learning activities. Blended learning employs traditional methods such as 
PAPER

A FrAMEWORK FOR COLlaborative NETWORKED LEARNING IN HIGHER EDUCATION: DeSIGN \& ANALYSIS

lecture and group-based learning with new approaches of online and networked learning through social media, thus observing individual differences in learning methods and knowledge accumulation.

Hope [6] identifies a set of factors for the prevalence of blended education such as: motivation of social communication among students, students and teachers, and teachers themselves; enhancement of learning achievements of students, by taking into account their pace, capacities and circumstances at any time and place; enhancement of students' ability to work in small groups and in a team spirit; enhancement of the quality of teaching materials, and teaching and learning skills.

Osguthorpe \& Graham [7] on the other hand, suggest that blended course structure varies depending on the goals that are included in the design, where the goals can be one or more of the following: pedagogical richness, access to knowledge, social interaction, personal agency, cost effectiveness, and ease of revision.

Community of Inquiry framework views blended learning from a socioconstructivist perspective $[4,5]$. In order to create a learning community, this model defines three major elements: teaching, cognitive, and social presence. According to this model teaching presence provides the structure to a course which directs cognitive and social presence.

Alternatively, the Blended Learning Curriculum (BLC) model presented by Huang, Ma, \& Zhang [8], defines three characteristics of blended learning as follows: flexible learning resources, learning diversity, and e-learning experiences. BLC model focuses on personalized learning and just-in-time transfer of skills.

\section{B. Collaborative Learning}

Collaborative learning by its nature depends on the sociocultural and activity theories [2,9]. There have been several attempts by researchers to define collaborative learning from different perspectives. Some researcher defined it based on the skills that is shared and transferred from one learner to an other in a group setting [10], others proposed a definition based on knowledge creation and sharing among learners [11]. There is also a definition that focuses on the methodologies and environments that facilitate sharing of common tasks [12]. One last definition that is worth mentioning states that collaboration learning is a "coordinated, synchronous activity that is the result of a continued attempt to construct and maintain a shared conception of a problem". This definition assumes that learning is greatly enhanced when the learners exist in a collaborative environment [13]. All of these definitions agree with the fact that people can learn through rich social interaction, as mentioned by [14].

A by-product of research on collaborative learning is the concept of learning community (LC) which consists mainly of three major components: interactivity, social context, and technologies [15]. Accordingly, collaborative learning can be considered as interaction between a learning community members for the purpose of learning [16]. Learning communities is said to play a major role in the success and persistence of higher education [17].

A separate field of research has emerged as a new educational paradigm, where computer-supported collaborative learning (CSCL) plays a significant role in enhancing the learning process [18]. CSCL research is focused on how learners interact together using computer mediated communication techniques. CSCL provides better understanding and more effective techniques to the applications of blended learning [19].

\section{Networked Learning}

Networked learning is a new form of CSCL that uses what is called "Network Environment" (connections), which assists collaboration between a group of learners; instructors and learners; educators; a learning community and its resources. Therefore, the network environment can help the participants in extending and developing their capabilities and understanding in ways that are meet their aspirations [20]. Networked learning is related to theories of distributed cognition [21,22] and is rising with the emergence of Web 2.0 technologies. Thus a learning environment is basically a physical environment that facilitates social interaction which allows learning to be distributed over space and time. From this concept, the central concern of networked learning is the argument about the relationship between using a technology and designing that technology [23]. The concept of networked learning has been described as "social intelligence design" based on three different aspects: mind, society, and matter [24]. Some researchers believe that the interaction and collaboration through a network transforms learning, memory, and intelligence from the individual level to the social network level $[25,26]$.

\section{BUILDING A COLLABORATIVE NETWORKED LEARNING FRAMEWORK}

Building a collaborative networked learning system for higher education is quite challenging. The process requires real collaboration and cooperation between involved universities. In order to proceed in such a system properly, software engineering methodology, namely, AGILE methodology is applied. The advantage of using Agile rather than the more traditional Water fall approach is that the former relies more on customer collaboration rather than contract negotiation. This concept seems very reasonable for our project which involves experts in education, administration, and information technology. In summary, the resulting system reflects the collaboration and cooperation efforts by those experts representing different higher educational institutions. The system's requirements and objectives can be stated as follows: Design and implement a comprehensive networked learning environment between several universities located in Jordan. The system must be able to create a learning community capable of collaborating at all levels: administration level, program level, instructor level, course level, research level, and student level. Figure 1 illustrates a general framework showing the interaction between major system's components in a networked learning community.

The system must be designed bearing in mind proprietary data to be located at each university servers. New contents generated as a result of collaboration such as unified courses are to be located in the central server, which is shared by all participants. The system must provide users with a full range of collaboration, communication, and learning tools. Security issues are important including user authentication, role assignments, and access privileges. The system must be flexible, upgradable, interoperable, and must accommodate new users, and new institutions that will be added in the future. 
Network analysis tools must be designed and made available to users and to administrators. Social networks are used to examine how institutions interact with each other, characterizing the many informal connections that link instructors together, as well as associations and connections between individual students at different institutions. In addition to SNA other methods such as online surveys and questionnaires are to be designed to measure the satisfaction of users at all levels.

We can summarize the objectives of the proposed system as follows:

1. Construct a higher educational collaboration network where decision makers, teachers, students, and researchers constitute a learning community.

2. Enhance learning pedagogy for undergraduate and postgraduate courses.

3. Share existing study programs, courses, resources, and activities.

4. Share and develop partnerships in research and project development.

5. Provide an environment for socialization.

6. Share news, events, and announcements.

7. Adopt best practices in teaching and learning according to national and international standards.

The next sections will introduce the design methodology using Agile approach.

\section{Design Stage}

Given the problem definition in the previous section along with the specified objectives, this section will focus on the design process using the Agile software engineering development methodology. This Agile methodology seems very suitable for our project as it relies more on customer collaboration rather than contract negotiation.

\section{A. Agile Software Development Methodology}

The Agile movement proposes alternatives to traditional project management and software development methodologies. Agile approaches are typically used in software development to help businesses respond to unpredictability [27].

One of the most important differences between the agile and sequential approaches is that sequential features distinct phases with milestones and deliverables at each phase, while agile methods have iterations rather than phases [281. Agile development methodology helps in assisting the track of a project during the development lifecycle. This is done through regular pieces of work called iterations, which must present a balanced product increment [27].

Agile project plans are based on features. Figure 2 shows the Agile software development milestones. Agile plans projects when main features will be submitted to construction and the most recent iteration tends to have additional details [29].

Agile project plans are arranged into time-bound iterations from $2-4$ weeks in length [28]. All of the compulsory work, from idea generating to a fully working product, is completed without preventing the work from being done in parallel. This gives stakeholders a better idea of the project progress, as they can use the end result when it becomes available [28].
The following, shown in Table 1, are the preliminary project milestones and deliverables established for our project:

TG1: Epics are defined including architecture at high level. Epics are a very large user scenario of the project that is eventually broken down into smaller scenarios.

TG2: Overall scope of the project is defined and estimated and our team can start detailing the project plans.

\section{B. Using Moodle 2.x LMS}

Moodle is a free open source learning management system written in PHP, and is deployable on most operating systems including Unix, Linux, Windows, and others. Moodle design is based on the constructivist and social constructivist approaches of learning thus providing a flexible environment for learning communities. Developers using Moodle have full access to the source code, Moodle Documents, and Help. There are several aspects of Moodle that makes suitable for this project.

Moodle has an easy, responsive, and personalized user interface suitable for desktop and mobile applications.

A comprehensive set of collaboration tools and activities such as forums, wikis, glossaries, and database activities.

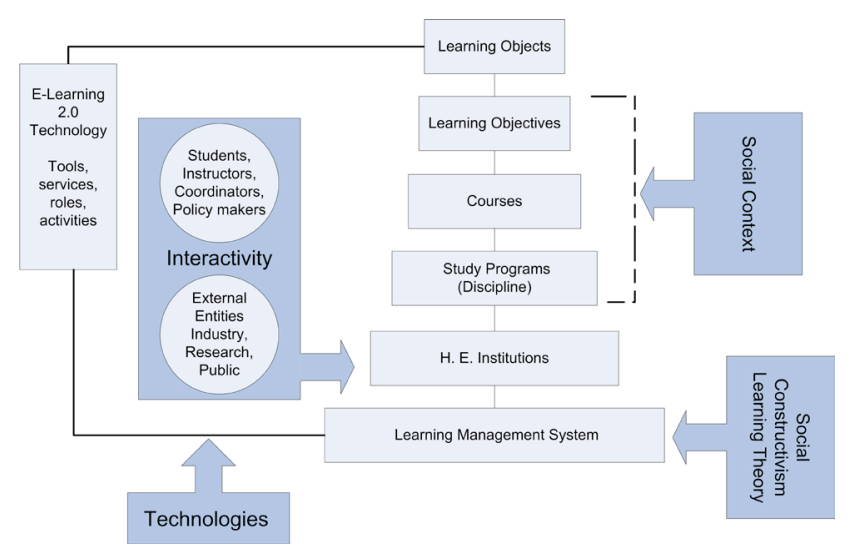

Figure 1. Framework for Networked Learning Community

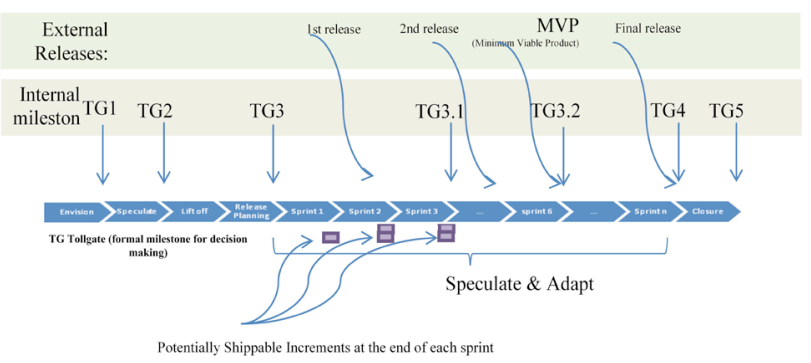

Figure 2. Agile Software Development Milestones [29]

TABLE I.

PRELIMINARY PROJECT MILESTONES WITH DESCRIPTION

\begin{tabular}{|lll|}
$\begin{array}{l}\text { Budget approved } \\
\text { for Speculation } \\
\text { phase }\end{array}$ & Milestone & $\begin{array}{l}\text { Resource is assigned for Initiation } \\
\text { phase to be completed }\end{array}$ \\
\hline $\begin{array}{l}\text { Initial product } \\
\text { backlog complete }\end{array}$ & TG1 & $\begin{array}{l}\text { Epics (user scenarios) are defined } \\
\text { including architecture at high level }\end{array}$ \\
\hline $\begin{array}{l}\text { Speculate phase } \\
\text { complete }\end{array}$ & TG2 & $\begin{array}{l}\text { Overall scope is defined and esti- } \\
\text { mated, Resource available, team can } \\
\text { start detailing the plans }\end{array}$ \\
\hline
\end{tabular}


An advanced calendar management system which can be automatically populated with new events, due dates and deadlines and which works on the system's level, user's level, or course level.

Advanced and simple to use features for administrators that include: customable site design and layout, detailed role and permission management, support open standards, bulk course creation and easy backup, detailed reporting and logs, high interoperability, and security.

Flexible course development features including: choosing appropriate pedagogy (instructor-lead, selfpaced, blended, or online), course collaboration tools, embedding external files, group management, multimedia files, marking and grading flexibility and in-line marking, peer and self assessment, and outcomes and rubrics.

Ability to observe peer's activities using online users block, and recent activities block.

Connection between participants using email, online messages, chatting, and push notification.

One of the major advantages of Moodle 2. $\mathrm{x}$ is the ability to connect several sites using Moodle as one network, thus creating what is called Moodle Community Hub (Fig. 3). Users can access all the nodes in the network transparently but securely (based on their privileges) in a single sign on.

\section{Unified Course Approach}

One of the objectives for the collaboration between different institutions is to learn and use best practices on all levels of learning. Involved institutions sit together and share their experience starting from the program of study level, going through course contents, and ending with course material. The result of this type of collaboration should be transformed into what we call a unified course. While the term "unified" could be misleading, we can define it as follows:

"A Unified Course is the result of sharing experience and expertise in all facets of a course. It is a generalized course containing core topics as well as other optional topics. It also covers pedagogy, course contents, course supportive material and reference, assessments, and so on. The course adheres to national and international accreditation bodies while satisfying the intended learning outcomes that are directly aligned with program objectives."

Working on the unified course is usually carried out during the planning and design phase of the project. A coordinator is assigned the task of putting together the final unified course, upload the results to the learning management system, and provide for future and continuous collaboration, maintenance, and updates. Figure 4 shows the unified course concept.

Other instructors from different universities are also asked to upload their regular courses, and course material, thus at this point the system will consist of a unified course existing on a central location, along with a number of other institution-specific courses located in different spaces, connected all together through the Learning management system.

New institutions who wish to join the network at this stage, can take advantage of the unified course to build their own specific courses, and at the same time may provide the network with feedback and suggestions to update the unified course.

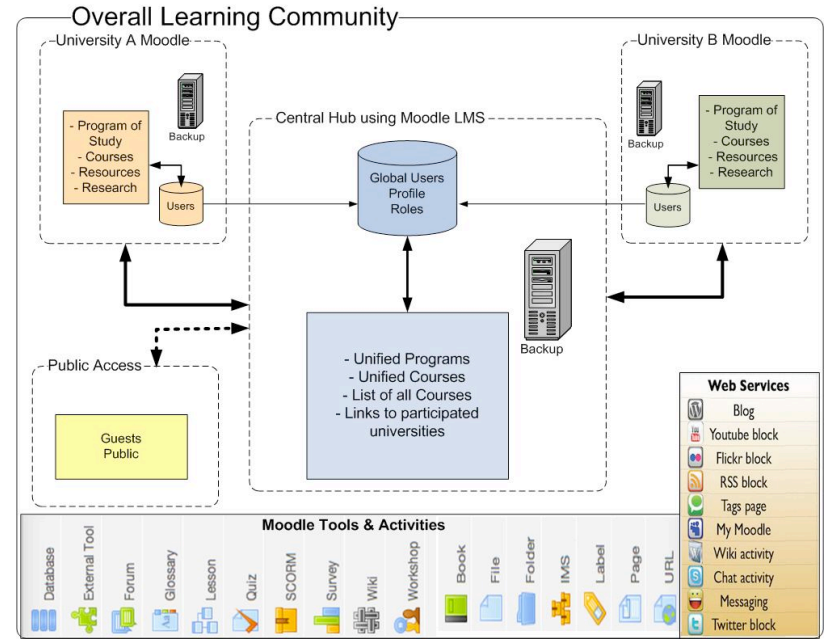

Figure 3. Collaborative network based on Moodle LMS

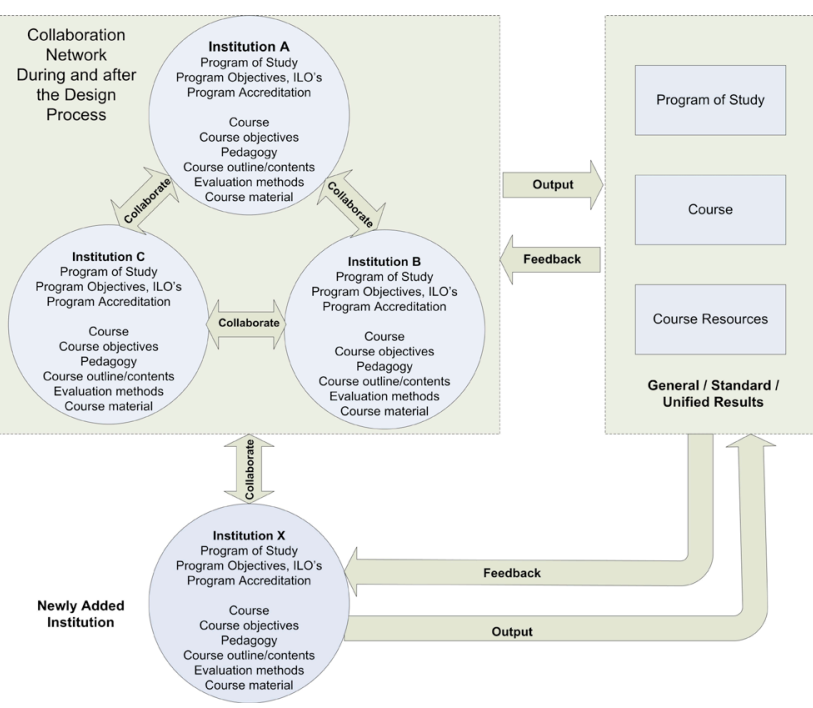

Figure 4. Collaborative network for the production of unified programs

Involved instructors from different universities can now enjoy a collaborative environment and can share teaching and research experiences. Students on the other hand, can communicate with their counterparts from within their institution and with other students from different universities. They can also communicate with other instructors, and get involved with lessons administered by different instructors.

\section{Collaboration from Student's Perspective}

Students are considered the main actors of the proposed learning system. Accordingly, special attention must be placed to provide students with an easy to use collaborative environment which can be useful and fun to use. Students can collaborate with fellow students from different universities using different activities. They can also collaborate with their instructors as well as other instructors from different universities. Students also have access to the unified courses and their resources. Figure 5 depicts student's access and collaboration.

\section{E. Collaboration from Teacher's Perspective}

Teachers have the opportunity to share their experience and teaching philosophy, not just on the course level, but 
also at the program level. They have access to the unified course as well as to other fellow teacher courses from different universities. Experienced teachers as well as newcomers can share teaching pedagogy, course text books, course outline, resources and references, and research ideas. Research groups amongst interested teachers can be easily formed, thus providing a fertile ground for future collaboration in research. Teachers can also stay in touch with their own students, as well as other students from different universities.

\section{F. Other issues related to design}

One of the strongest features of using Moodle LMS in the implementation of networked learning is its flexibility in controlling user access. The system permits administrators, teachers, and content creators to totally control who, what, when, and how others access their contents. Using this advanced feature of Moodle truly helps in organizing the most complex network. For any user to have access his/her username (profile) must exist within the system's database which can be accomplished in a variety of methods such as direct uploading, LDAP authentication, or online registration. Once a user profile exists within the system's database, it can be assigned any role by the administrator.

In order to manage users and their roles within a complex network consisting of users from different universities, we view the user database as a hierarchy.

\section{Analysis Stage}

\section{A. Social Network Analysis(SNA)}

The second part of the framework is the analysis of the participant's interactivity that involve in the collaborative network learning within and among the institutions. This part intends to utilize the social network analysis technique that assists in understanding the interactivity of participants' networked learning. SNA aims to identify the relationships based on how the actors are connected with each other [30, 31]. For example, Moore (1989) [32] identifies that student's interactivity are three types of interactions in learning environments: learner-content, learnerinstructor, and learner-learner.

We propose that SNA can help in representing and mapping participants' relationships in the NL. This leads on to generating additional analytical data about the interactivity between the members of NL, and understanding behavior in NL environments. In our case, SNA is used to understand the flow of information, and the exchange of resources or activities among members of NL. Our primary focus in the analysis part is to study the exchange messages in the course activities and resources.

SNA can be used to visualize and represent the social environment as a network based on the relationships by creating a graphical representation called a sociogram. The nodes of the sociogram represent the participants and the edges represent the connections between the nodes. The major analytical data from SNA calculates the cohesion of a network. The most important measures of SNA are "density" and "centrality. Density as a measure is a degree of the overall 'connections' between the participants. The density of a network is defined as the number of edges in a network divided by the maximum number of possible edges [30]. The value of density varies between 0

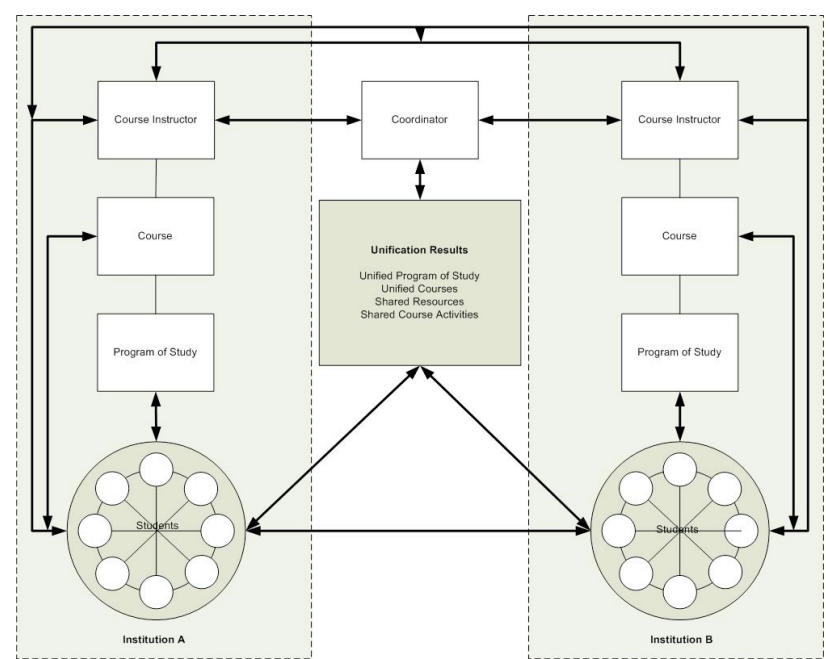

Figure 5. Collaboration Diagram showing a sample of two institutions, one program of study, and an instance of one course for each

and $100 \%$ which means that the higher the density value is, the more interactions exist within the network [30, 33]. Centrality as a measure provides the participant that plays the central role in the network [31]. In our, case, this can reflects on the institution, course activity, resource, instructor, and student.

This centrality can be done for each participant in the network by measuring the number "in-degree" and "outdegree" values. In-degree centrality counts the number of messages received to certain participant, whereas outdegree counts number of messages a participant has sent to other participants [33].

The SNA technique is used commonly in sociology and organizational studies, but it has been utilized in varies NL/CSCL research to study group interaction and, communication [34]. For example, Martinez, Dimitriadis, Rubia, Gomez, and de la Fuente (2003) [35] found that teacher's presence has an effect on the network density. Daradoumis, Martinez-Mones, and Xhafa (2004) [36] used SNA to assess and identify the performance of the most effective virtual learning groups.

\section{B. Evaluation for collaborative learning network}

The evaluation stage of the collaborative learning network frameworks intends to quantitatively examine the relationships between perceived collaborative learning with participant's satisfaction in different unified courses. For example, LaPoint and Gunawardena (2004) [37] denote that student satisfaction can be considered as an effective measure of learning outcomes. This will be implemented by preparing a questionnaire that will discover what participants' opinions and attitudes are towards the unified course contents, activities and resources. Participants will be people with various roles, including students, from different institutions involved in the networked learning. Results will be analyzed using different statistical techniques.

\section{CONCLUSION}

The work presented in this paper has been guided by the authors' vision to enhance higher education in Jordan through collaborative work involving a number of local universities. The enhancement of higher education was translated into several goals and objectives to be satisfied 
through the implementation of a system which is conceived, planned, and implemented as a result of shared knowledge, experience, expertise, and resources of participating universities. In order to arrive at a comprehensive system which successfully connects hundreds of stakeholders, starting from top policy makers down to the student level, the authors realize the need to convert the actual implementation steps into a general framework. The framework which is based in principle on previously studied learning theories provides interested researchers with general guidelines and procedures which can be easily customized to fit future learning projects.

\section{REFERENCES}

[1] World Bank, Education Reform for the Knowledge Economy II Project Information Document. World Bank, Washington, DC., 2009.

[2] G. Issa, SM. Hussain, H Al-Bahadili,"Competition-Based Learning: A Model for the Integration of Competitions with ProjectBased Learning using Open Source LMS, " International Journal of Information and Communication Technology Education (IJICTE), Vol. 10, No.1, IGI Publishing, 2014, pp.1 - 13.

[3] L.S. Vygotsky, Mind in Society. The Development of Higher Psychological Processes. M. Cole, V. John-Steiner, S. Scribner \& E. Souberman, Eds. Cambridge, Massachusetts, Harvard University Press, 1978.

[4] D. R. Garrison, N. D. Vaughan. Blended learning in higher education: Framework, principles, and guidelines. John Wiley \& Sons, 2008.

[5] D. R. Garrison, M. Cleveland-Innes, and T. S. Fung. "Exploring causal relationships among teaching, cognitive and social presence: Student perceptions of the community of inquiry framework." The Internet and Higher Education, vol 13, no.1, 2010, pp. 31-36. http://dx.doi.org/10.1016/j.iheduc.2009.10.002

[6] A. Hope, "Factors for success in dual mode institutions." Commonwealth of Learning, Vancouver, Canada, 2006.

[7] R. T. Osguthorpe, and R. G. Charles. "Blended Learning Environments: Definitions and Directions." Quarterly Review of Distance Education vol. 4, no. 3, 2003, pp. 227-33.

[8] R. Huang, M. Ding, and H. Zhang. "Towards a design theory of blended learning curriculum." Hybrid Learning and Education, Springer Berlin Heidelberg, 2008, pp. 66-78.

[9] A. N. Leontiev, Actividade, consciência e personalidade. Buenos Aires: Ciências Del Honbre, 1978.

[10] P. Dillenbourg, "What do you mean by collaborative learning?." In Collaborative-learning: Cognitive and computational approaches, P. Dillenbourg, Eds., Oxford: Elsevier, 1999, pp. 1-19.

[11] R. Mitnik, M. Recabarren, M. Nussbaum, and A. Soto. "Collaborative robotic instruction: A graph teaching experience." Computers \& Education, vol. 53, no. 2, 2009, pp. 330-342 http://dx.doi.org/10.1016/j.compedu.2009.02.010

[12] M. M. Chiu,. "Flowing toward correct contributions during group problem solving: A statistical discourse analysis." the Learning Sciences vol. 17, no. 3, 2008, pp. 415-463.

[13] J. Roschelle, and S. Teasley, The construction of shared knowledge in collaborative problem solving, O'MALLEY C., Computer-Supported Collaborative Learning, 1995.

[14] C. Tu, and C. Michael, "Building active online interaction via a collaborative learning community." Computers in the Schools, vol. 20, no. 3, 2003, pp. 51-59. http://dx.doi.org/10.1300/ J025v20n03 07

[15] C. Tu, Online collaborative learning communities: Twenty-one designs to building an online collaborative learning community. Libraries Unlimited, 2004.

[16] P. Vesely, B. Lisa, and S. John, "Key elements of building online community: Comparing faculty and student perceptions." MERLOT Journal of Online Learning and Teaching, vol. 3, no. 3, 2007, pp. 234-246.

[17] P. Shea, L. Chun, and P. Alexandra, "A study of teaching presence and student sense of learning community in fully online and webenhanced college courses." The Internet and Higher Education, vol. 9, no. 3, 2007, pp. 175-190. http://dx.doi.org/10.1016/ j.iheduc. 2006.06 .005
[18] P. Resta, and L. Thérèse, "Technology in support of collaborative learning." Educational Psychology Review, vol. 19, no. 1, 2007, pp. 65-83. http://dx.doi.org/10.1007/s10648-007-9042-7

[19] G. Stahl, K. Timothy, and S. Dan, Computer-supported collaborative learning: An historical perspective, Cambridge handbook of the learning sciences, 2006.

[20] S. Banks, P. Goodyear, V. Hodgson, and D. McConnell, "Introduction to the special issue on Advances in Research on Networked Learning." Instructional Science, vol. 3, 2003, pp. 1-6.

[21] C. Bereiter, "Design research for sustained innovation." Cognitive studies, bulletin of the Japanese cognitive science society, vol. 9, no. 3, 2002, pp. 321-327.

[22] R. Sawyer, Social emergence: Societies as complex systems., Cambridge University Press, 2005. http://dx.doi.org/10.1017/ CBO9780511734892

[23] C. Jones, "Networked Learning: Stepping Beyond the Net Generation and Digital Natives.", In Exploring the Theory, Pedagogy and Practice of Networked Learning, Springer, 2012, pp. 27-41. http://dx.doi.org/10.1007/978-1-4614-0496-5 2

[24] A. Heylighen, et al., "Distributed (design) knowledge exchange.", $A i$ \& Society, vol. 22, no. 2, 2007, pp. 145-154. http://dx.doi.org/10.1007/s00146-007-0122-5

[25] G. Siemens, Learning and knowing in networks: Changing roles for educators and designers., ITFORUM for Discussion, 2008.

[26] S. Downes, "Places to go: Connectivism \& connective knowledge." Innovate: Journal of Online Education, vol. 5, no.1, 2008.

[27] A. Abran, J.W. Moore, Guide to the Software Engineering Body of Knowledge (SWEBOK $\AA)$, IEEE Computer Society 2004 Guide,

Angela Burgess, 2004.

[28] B. Boehm, R. Turner, "Management Challenges to Implement Agile Processes in Traditional Development Organizations", IEEE Software vol. 22, no. 5, 2005, pp. 30-39. http://dx.doi.org/10.1109/MS.2005.129

[29] Lee, Seiyoung; Yong, Hwan-Seung. Distributed agile: project management in a global environment. Empirical Software Engineer. 2010.

[30] J.Scott, Social network analysis: A handbook. London: Sage, 1999.

[31] S.Wasserman, and K. Faust, Social network analysis: Methods and applications. Cambridge: Cambridge University Press, 1997.

[32] M. Moore, "Three Types of Interaction", The American Journal of Distance Education, vol. 3, no. 2, pp. 1-7, 1989. http://dx.doi.org/10.1080/08923648909526659

[33] S.Borgatti, M. Everett, and L.Freeman, Ucinet for Windows: Software for Social Network Analysis. Harvard, MA: Analytic Technologies, 2002.

[34] C. Haythornthwaite , "Exploring Multiplexity: Social Network Structures in a Computer-Supported Distance Learning Class", The Information Society, vol. 17, 2001, pp. 211-226. http://dx.doi.org/10.1080/01972240152493065

[35] A. Martinez, Y., Dimitriadis, B., Rubia, E. Gomez, and P., de la Fuente, "Combining Qualitative Evaluation and Social Network Analysis for the Study of Classroom Social Interactions", Computers \& Education, vol 41, no. 4, 2003, pp. 353-368. http://dx.doi.org/10.1016/j.compedu.2003.06.001

[36] T. Daradoumis, T., Martinez-Mones, and F. Xhafa, "An Integrated Approach for Analyzing and Assessing the Performance of Virtual Learning Groups", in Lecture notes in computer science, G. de Vreede, L. A. Guerrero, \& G. M. Raventós, Eds, Berlin Heidelberg New York: Springer, 2004, pp. 289-304.

[37] D. LaPointe, and C. Gunawardena, "Developing, Testing and Refining of a Model to Understand the Relationship Between Peer Interaction and Learning Outcomes in Computer-Mediated Conferencing", Distance Education, vol, 25, no. 1, 2004, pp. 83-106. http://dx.doi.org/10.1080/0158791042000212477

\section{AUTHORS}

Ghassan F. Issa, Haya A. El-Ghalayini, Ahmad F. Shubita, and Mohammed H. Abu-Arqoub are with University of Petra, Amman, Jordan.

Submitted 22 April 2014. Published as re-submitted by the authors 26 May 2014. 